\title{
ANALISIS KETERSEDIAAN BAHAN BAKU IKAN TERHADAP KEBERADAAN COLD STORAGE DI PPP PONDOKDADAP, SENDANG BIRU, MALANG - JAWA TIMUR
}

Setya Budi Karsana, Mercy Patanda

Fakultas Perikanan dan Ilmu Kelautan, Universitas Satya Negara Indonesia.

\section{ABSTRAK}

Tujuan penelitian ini adalah 1) Mengidentifikasi jenis-jenis ikan ekonomis penting yang didaratkan di PPP Pondokdadap, Sendang Biru. 2) Menghitung produksi hasil tangkapan ikan ekonomis penting yang didaratkan di PPP Pondokdadap, Sendang Biru. 3) Menghitung ketersediaan bahan baku ikan untuk pemenuhan kebutuhan cold storage di PPP Pondokdadap, Sendang Biru.

\section{PENDAHULUAN}

Unit pengolahan ikan yang berlokasi di suatu pelabuhan perikanan atau sekitarnya umumnya menggunakan sebagian atau keseluruhan bahan bakunya dari pelabuhan perikanan tersebut. Ketersediaan bahan baku secara kontinyu diperlukan agar pelaku usaha mendapatkan kepastian dalam usahanya. Industri akan lebih menguntungkan apabila dekat dengan sumber bahan baku (Renner 1957 dalam Hasvia, 2000). Jika industri pengolahan jauh dari bahan baku maka sejak ikan didaratkan perlu penanganan yang lebih untuk menjaga mutu hasil tangkapan yang dijadikan sebagai bahan baku, seperti pemberian es yang tepat di tempat penampungan ikan sementara sebelum ikan didistribusikan, penggunaan sarana transportasi berpendingin yang memadai dan penambahan biaya distribusi sampai ke unit pengolahan ikan.

Cold storage di Pondokdadap dibangun bertujuan untuk menjaga mutu ikan, memotong rantai produksi, mengurangi biaya produksi dan mendorong peningkatan nilai tambah produk hasil perikanan Indonesia. Keberadaan cold storage ini akan optimal beroperasi apabila terjamin ketersediaan bahan baku atau hasil tangkapan ikan sehingga diperlukan informasi jenis-jenis ikan ekomonis penting apa saja dan jumlah produksi hasil tangkapan yang didaratkan.

\section{METODE PENELITIAN}

Kegiatan penelitian ini dilaksanakan pada bulan November sampai dengan Desember 2018 bertempat di PPP Pondokdadap, Sendang Biru, Malang, Jawa Timur.

Metode yang digunakan pada penelitian ini adalah metode studi kasus dengan aspek yang diteliti yaitu jenis-jenis ikan ekonomis penting, jumlah produksi hasil tangkapan sebagai bahan baku cold storage di PPP Pondokdadap, Sendang Biru Malang, Jawa Timur. Analisis data yang dilakukan: 1) Secara deskriptif melalui penyajian tabel dan grafik untuk jenis-jenis ikan ekonomis penting. 2) Analisis tren dan perhitungan Cacth Per Unit Effort (CPUE) untuk produksi hasil tangkapan. 3) Memperhitungkan data volume produksi, tingkat utilitas UPI di lokasi, dan rencana produk akhir untuk ketersediaan bahan baku cold storage. 


\section{HASIL DAN PEMBAHASAN}

Berdasarkan data dari PPP Pondokdadap tahun 2018, terdapat 4 (empat) jenis ikan dominan yang didaratkan di PPP Pondokdadap adalah tuna (Thunnus sp.), cakalang (Katsuwonus pelamis), tongkol (Euthynnus spp.) dan layang (Decapterus spp.). Volume dan nilai produksi dari 4 (empat) jenis ikan ekonomis penting di PPP Pondokdadap dapat dilihat pada Tabel 1.

Tabel 1. Volume dan Nilai Produksi Ikan Ekonomis Penting di PPP Pondokdadap Tahun 2018

\begin{tabular}{lcccr}
\hline \multicolumn{1}{c}{ Jenis Ikan } & $\begin{array}{c}\text { Volume } \\
\text { produksi } \\
\text { (ton) }\end{array}$ & $\begin{array}{c}\text { Persentase } \\
\text { (\%) }\end{array}$ & $\begin{array}{c}\text { Nilai produksi } \\
\text { (x 1000 rupiah) }\end{array}$ & $\begin{array}{c}\text { Persentase } \\
(\%)\end{array}$ \\
\hline $\begin{array}{l}\text { Tuna } \\
\text { (Thunnus sp) }\end{array}$ & $1.400,28$ & 10,01 & 36.135 .509 .680 & 23,34 \\
\hline $\begin{array}{l}\text { Cakalang } \\
\text { (Katsuwonus pelamis) }\end{array}$ & $3.721,65$ & 26,62 & 47.875 .048 .310 & 30,93 \\
\hline $\begin{array}{l}\text { Tongkol } \\
\text { (Euthynnus spp.) }\end{array}$ & $4.123,22$ & 29,49 & 35.553 .750 .892 & 22,97 \\
\hline $\begin{array}{l}\text { Layang } \\
\text { (Decapterus spp.) }\end{array}$ & $3.774,71$ & 27,00 & 27.991 .062 .800 & 18,08 \\
\hline $\begin{array}{l}\text { Jumlah Keseluruhan } \\
\text { Produksi PPP } \\
\text { Pondokdadap }\end{array}$ & $13.982,35$ & 100 & 154.802 .359 .882 & 100,00 \\
\hline
\end{tabular}

Sumber : Hasil Penelitian (2018)

Berdasarkan Tabel 1 diketahui bahwa keempat ikan dikategorikan sebagai jenis-jenis ikan ekonomis penting. Hal ini sesuai dengan penelitian Genisa (1999) yang menyatakan bahwa ikan tuna, cakalang, dan tongkol termasuk ikan ekonomis penting karena memiliki kualitas yang baik dan nilai pasaran yang tinggi. Ikan layang dikategorikan ikan ekonomis penting karena meskipun memiliki kualitas yang lebih rendah dan harga relatif lebih murah namun daya produskinya tinggi atau melimpah sehingga dapat dimanfaatkan sebagai bahan baku alternatif untuk memenuhi operasional cold storage.

Berdasarkan analisis, tren produksi hasil tangkapan ikan tuna, cakalang, tongkol, dan layang di PPP Pondokdadap dapat dilihat pada Gambar 1.

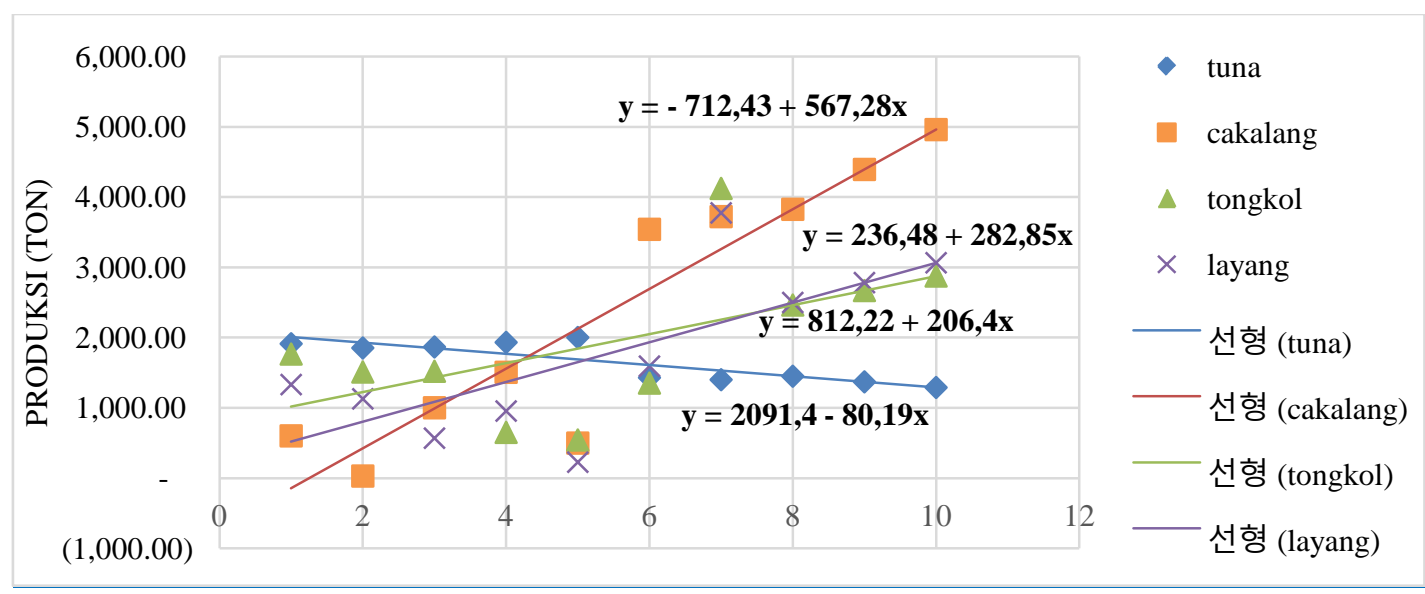

Gambar 1. Grafik Tren Produksi Hasil Tangkapan Ikan Tuna, Cakalang, Tongkol dan Layang di PPP Pondokdadap 
Tren produksi hasil tangkapan ikan tuna di PPP Pondokdadap cenderung menurun. Penurunan ini disebabkan karena permintaan pasar yang tinggi terhadap ikan tuna sehingga menyebabkan tingginya intensitas penangkapan ikan tuna. Penelitian sebelumnya juga menyebutkan bahwa kondisi sumber daya ikan di sekitar perairan Samudera Hindia dan Samudera Pasifik sudah mengalami full exploited (FAO, 2007 dalam Saputra, 2011).

Selain analisis tren, Catch per Unit Effort (CPUE) dapat menggambarkan sumber daya ikan di PPP Pondokdadap. Nilai CPUE ikan tuna, cakalang, tongkol dan layang periode tahun 2014 - 2018 di PPP Pondokdadap dapat dilihat pada Gambar 2.

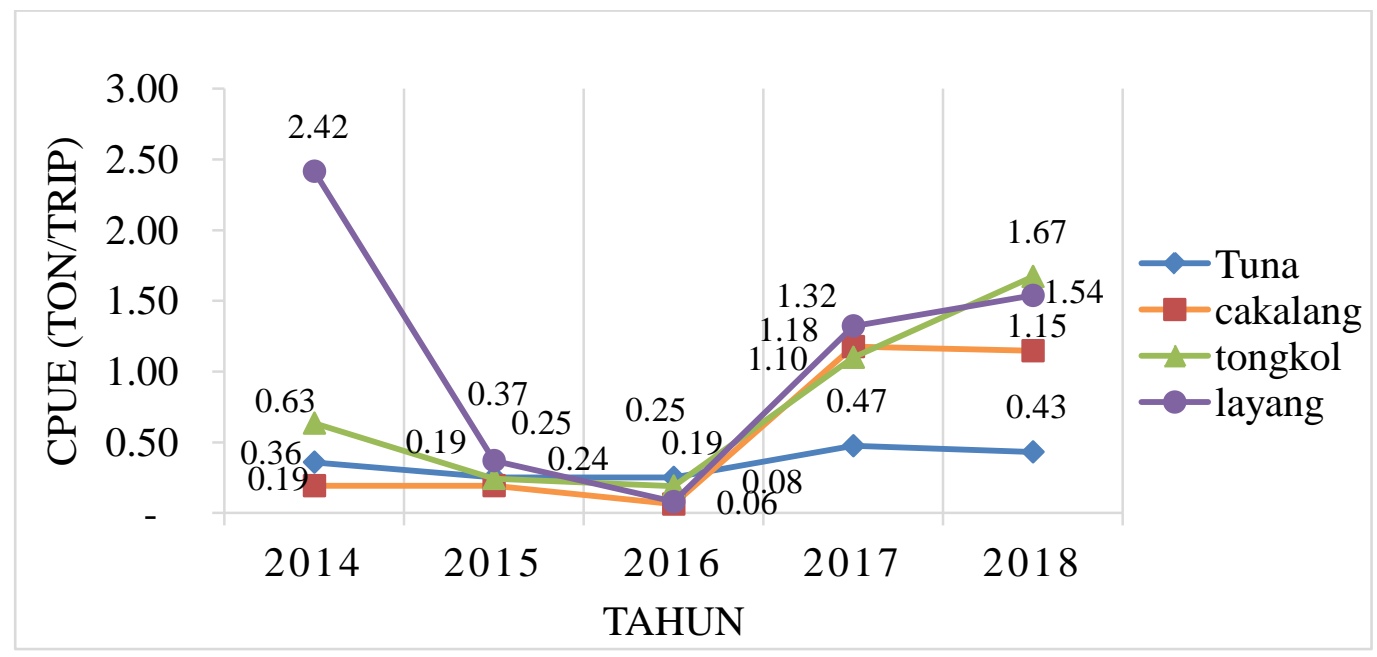

Gambar 2. Nilai Catch per Unit Effort (CPUE) Ikan Tuna, Cakalang, Tongkol dan Layang Periode Tahun 2014 - 2018 di PPP Pondokdadap

Hasil produksi ikan tuna tertinggi terjadi pada tahun 2016 yaitu sebesar 2.2001,24 ton dengan tingkat upaya sebanyak 7.974 trip dan nilai CPUEnya sebesar 0,25 ton/trip. Produksi ikan tuna terendah terjadi pada tahun 2018 dengan hasil produksi 1.400,28 ton dengan tingkat upaya sebanyak 3.246 trip dan nilai CPUEnya sebesar 0,43 ton/trip. Hal ini menunjukkan bahwa meningkatnya nilai CPUE karena berkurangnya upaya penangkapan. Tingkat perubahan nilai CPUE yang terjadi tidak selalu berbanding lurus, dimana pada tingkat upaya besar belum tentu besar pula hasil produksi justru semakin kecil dan sangat tergantung dari produktivitas dan tergambar pada CPUE (Listiani. et al, 2017).

Menurut Jaya et al., 2017, pada tahun 2013 sampai 2015 tren CPUE (Cacth Per Unit Effort) untuk perikanan tuna mengalami penurunan yang cukup drastis, yaitu telah terjadi penurunan CPUE lebih dari 25\% dalam 1 (satu) tahun. Penurunan CPUE ini mengindikasikan bahwa tingkat pemanfaatan daerah penangkapan ikan tuna di daerah perairan Sendang Biru sudah mengalami over fishing. Oleh sebab itu, menjaga agar potensi sumberdaya ikan tuna agar tetap lestari maka perlu dilakukan pengelolaan perikanan secara benar seperti membatasi ijin penangkapan ikan tuna.

Berdasarkan perhitungan Cacth Per Unit Effort (CPUE), pada tahun 2017 sampai 2018 terjadi peningkatan nilai produksi dan nilai CPUE pada ikan cakalang, tongkol dan layang meningkat meskipun effort/upaya penangkapan 
bertambah. Hal ini menunjukkan bahwa tingkat pemanfaatan ikan masih belum optimal. Secara umum laju eksploitasi ikan cakalang di Selatan Jawa masih di bawah tingkat pemanfaatan optimum (Zedta, et al, 2017).

Produksi ikan-ikan ekonomis penting di PPP Pondokdadap pada Tahun 2018 sebesar 13.019,87 ton. Estimasi kebutuhan bahan baku yang dapat diserap untuk pemenuhan kebutuhan cold storage per hari sebesar 7,81 ton. Estimasi ketersediaan bahan baku dan kapasitas produksi dapat dilihat pada Tabel 2.

Tabel 2. Estimasi Ketersediaan Bahan Baku Ikan dan Kapasitas Produksi Cold Storage

\begin{tabular}{|c|c|c|c|c|c|c|}
\hline \multirow{2}{*}{$\begin{array}{l}\text { Jenis Bahan } \\
\text { Baku }\end{array}$} & $\mathrm{Pi}$ & I & $\mathrm{T}$ & EB & $\mathrm{Pa}$ & KP \\
\hline & $\begin{array}{l}\text { Produksi } \\
\text { (ton) }\end{array}$ & $\begin{array}{c}\text { Nilai } \\
\text { Indeks } \\
(\%)\end{array}$ & $\begin{array}{l}\text { Operasional } \\
\text { (hari) }\end{array}$ & $\begin{array}{c}\text { Estimasi } \\
\text { Bahan } \\
\text { Baku } \\
\text { (ton/hari) }\end{array}$ & $\begin{array}{l}\text { Rendemen } \\
\text { Produk } \\
\text { Akhir (\%) }\end{array}$ & $\begin{array}{l}\text { Kapasitas } \\
\text { Produksi } \\
\text { (ton/hari) }\end{array}$ \\
\hline $\begin{array}{l}\text { Tuna } \\
\text { (Thunnus sp.) }\end{array}$ & $1.400,28$ & 15 & 250 & 0,84 & 40 & 0,34 \\
\hline $\begin{array}{l}\text { Cakalang } \\
\text { (Katsuwonus } \\
\text { pelamis) }\end{array}$ & $3.721,65$ & 15 & 250 & 2,23 & 98 & 2,19 \\
\hline $\begin{array}{l}\text { Tongkol } \\
\text { (Euthynnus spp.) }\end{array}$ & $4.123,22$ & 15 & 250 & 2,47 & 98 & 2,42 \\
\hline $\begin{array}{l}\text { Layang } \\
\text { (Decapterus spp.) }\end{array}$ & $3.774,71$ & 15 & 250 & 2,26 & 98 & 2,22 \\
\hline Jumlah & $13.019,87$ & & & 7,81 & & 7,17 \\
\hline
\end{tabular}

Sumber: Hasil Penelitian (2018)

Produk akhir atau produk yang disimpan di dalam cold storage adalah sebesar 7,17 ton/hari. Hal ini diperoleh dari ikan tuna loin beku sebanyak 0,34 ton/hari, ikan tongkol utuh beku sebanyak 2,42 ton/hari, ikan cakalang utuh beku sebanyak 2,19 ton/hari dan ikan layang utuh beku sebanyak 2,22 ton/hari. Cold storage di PPP Pondokdapap memiliki alat pembekuan (Air Blast Freezer-ABF) dengan kapasitas produksi 5 ton per siklus dimana untuk operasional atau proses produksi cold storage minimal 50\% atau sebesar 2,5 ton/siklus (per 8 jam). Oleh sebab itu bahan baku untuk pemenuhan kebutuhan operasi cold storage masih dapat dipenuhi dari bahan baku yang tersedia.

\section{KESIMPULAN DAN SARAN}

Kesimpulan pada penelitian ini yaitu: 1) Jenis-jenis ikan ekonomis penting yang didaratkan adalah tuna (Thunnus sp), cakalang (Katsuwonus pelamis), tongkol (Euthynnus spp.) dan layang (Decapterus spp.). Produksi ikan ekonomis penting di PPP Pondokdadap selama periode tahun 2014 - 2018 bervariasi. Tren produksi ikan tuna cenderung menurun dan meningkatnya Cacth per Unit Effort (CPUE) ikan tuna karena berkurangnya effort/upaya penangkapan. Tren produksi ikan cakalang, tongkol dan layang cenderung meningkat. Nilai CPUE ikan cakalang, tongkol dan layang juga meningkat meskipun effort/upaya penangkapan bertambah. 3) Ketersediaan bahan baku ikan yang dapat diserap sebesar 7,81 ton/hari sehingga masih mencukupi untuk pemenuhan kebutuhan cold storage yang memiliki alat pembekuan sebesar 5 ton/siklus. 


\section{DAFTAR PUSTAKA}

Genisa, A.S. 1999. Pengenalan Jenis - Jenis Ikan Laut Ekonomis Penting di Indonesia. Jurnal Oseana 24 (1): 17-38

Hasvia. 2000. Kajian Faktor-faktor Penentuan Lokasi Industri di Klaten. Program Pasca Sarjana Magister Perencanaan Kota dan Daerah (MPKD). Universitas Gajah Mada. Yogyakarta

Jaya, M. M., Wiryawan, B., Simbolon D. 2017. Analisis Tingkat Pemanfaatan Sumberdaya Ikan Tuna dengan Metode Spawning Potential Ratio di Perairan Sendangbiru. Jurnal Ilmu dan Teknologi Kelautan Tropis 9 (2): 597-604

Listiani A., Wijayanto, D., Jayanto, B.B. 2017. Analisis CPUE (Catch Per Unit Effort) dan Tingkat Pemanfaatan Sumberdaya Perikanan Lemuru (Sardinella Longiceps) di Perairan Selat Bali. Jurnal Undip 1 (1): 1-9

Saputra, S.W. 2011. Produktivitas dan Kelayakan Usaha Tuna Longliner di Kabupaten Cilacap. J. Saintek Perikanan, 6 (2): 84-91.

Zetda, R. R., Tampubolon, A. P, Novianto, D. 2017. Estimasi Parameter Populasi Ikan Cakalang (Katsuwonus pelamis, Linnaeus, 1758) di Perairan Samudera Hindia. Bawal, 9 (3): 163-173. 